\title{
Intractable Diarrhoea with Recurrent Hypernatremia: Experiences of Management Difficulties from a Diarrhoeal Treatment Centre of Bangladesh
}

\author{
Lubaba Shahrin*, Mohammod Jobayer Chisti, Sayeeda Huq, M Munirul Islam, Abu Syed Golam Faruque, Shafiqul Alam Sarker, Fahmida \\ Tofail and Tahmeed Ahmed
}

International Centre for Diarrhoeal Disease Research, Bangladesh

\begin{abstract}
Background: Intractable diarrhoea of childhood is one of the most life-threatening chronic conditions and its management is always intriguing even in highly advanced critical care set-up.

Objective: To describe the clinical course of a 3 months old baby suffering from intractable diarrhoea and recurrent hypernatremia. This case focuses difficulties due to diagnostic limitation as well as management constrains of young children with intractable diarrhoea in the context of limited resources.

Case brief: The young infant was admitted in the Intensive Care Unit (ICU) of Dhaka Hospital in the International Centre for Diarrhoeal Disease Research, Bangladesh (icddr,b) with the complaints of watery diarrhoea since birth, hypernatremic (serum sodium:168 mmol/L) seizure, and severe acute malnutrition. Hypernatremia was corrected within 5 days of admission (corrected serum sodium: $147 \mathrm{mmol} / \mathrm{L}$ ) by using only Oral Rehydration Salts solution (ORS). To assess any possible structural damage of the brain as a result of hypernatremia, we performed Magnetic Resonance Imaging Scan of the brain. The scan revealed right sided bleeding in choroid plexus. Although, the diarrhoea was initially improved by diet as per world health organization dietary algorithm (beginning with low lactose followed by lactose-free chicken-based diet), it relapsed later. Subsequently the infant developed nosocomial infection, worsening of diarrhoea and recurrent hypernatremia. For the management of intractable diarrhoea, the patient had to stay in hospital for a prolonged period that may have led to nosocomial infection. It was difficult to manage due to severe malnutrition, young age and on-going diarrhoea. The patient finally expired on $39^{\text {th }}$ day of admission due to septic shock.
\end{abstract}

Conclusion: Patient with intractable diarrhoea may present with other co-morbidities like malnutrition, hypernatremia and sepsis that make the management very difficult. In low income countries, where total parental nutrition facility is unavailable, a systematic approach needs to develop to reduce intractable diarrhoea related mortality.

Keywords: Intractable diarrhoea of infancy; Hypernatremia; Malnutrition; Bangladesh; Case report

\section{Introduction}

Most diarrhoeal episodes are self-limiting and usually resolve within 7 days, but those failing to resolve within 2 weeks, termed persistent diarrhoea, carry a substantial diarrhoea-related morbidity and poses a significant management problem. It accounts for $36 \%$ to $54 \%$ of diarrhoea related deaths [1]. In developing countries. Intractable diarrhoea of infancy is a term first adopted by Avery et al. [2] which is defined as a syndrome, characterised by diarrhoea occurring in newborn younger than 3 months lasting for more than 2 weeks with three or more negative stool cultures for bacteria or parasites [2]. According to World Health Organization, worldwide the prevalence of diarrhoea that last greater than 2 weeks ranges from $3 \%$ to $20 \%$ in children [3]. There are a list of causes of infantile intractable diarrhoea. In developed countries, it is more likely to be due to underlying diseases, such as celiac disease or other food allergy, but in developing country, it usually develops in association with serial enteric infections without remission between episodes [4,5]. Irrespective of the etiologies, the prognosis of intractable diarrhoea is considered to be poor due to development of associated morbidities like malnutrition, recurrent infection and electrolyte imbalance [6]. Diarrhoea associated with hypernatremia (serum sodium $\geq 150 \mathrm{mmol} / \mathrm{L}$ ) in children under five years old is reported as an independent predictor of death in developing [7]. As a complication of hypernatremia or during the process of correction, brain shrinhage may induced causing vascular rupture, cerebral bleeding and permanent neurological damage or death $[8,9]$. The factors associated with hypernatremia in intractable diarrhoea are still unclear. There are some reports on successful management of acute watery diarrhoea with severe hypernatremia $(>170 \mathrm{mmol} / \mathrm{L})$ [10], but there are no published data on the prevalence or management with recurrent hypernatremia in an infant with intractable diarrhoea. It is also not known whether the hypernatremia is iatrogenic from fluid replacement or due to some other causes. Malnutrition itself significantly predisposes children to a greater incidence of diarrhoea and often prolongs duration of diarrhoea [11]. The management course may also be complicated by nosocomial infection as a result of prolonged hospitalization. The purpose of this paper is to present a case on intractable diarrhoea complicated with recurrent hypernatremia and other co-morbidities that may be difficult to manage even in an expert diarrhoeal treatment centre in developing country. Lessons learnt from this subject may help clinicians in managing such children especially in resource-limited settings.

\section{Case History}

A 3-months old exclusively breastfed male baby from a middle

*Corresponding author: Lubaba Shahrin, Centre for Nutrition and Food Security (CNFS), International Centre for Diarrhoeal Disease Research, Bangladesh, 68 Shaheed Tajuddin Ahmed Sarani, Mohakhali, Dhaka 1212, Bangladesh, Tel: +880-29827104 ; Fax: +880-2-9827104 ; E-mail: lubabashahrin@icddrb.org

Received October 02, 2014; Accepted November 03, 2014; Published Novembe 05, 2014

Citation: Shahrin L, Chisti MJ, Huq S, Munirul Islam M, Golam Faruque AS, et al. (2014) Intractable Diarrhoea with Recurrent Hypernatremia: Experiences of Management Difficulties from a Diarrhoeal Treatment Centre of Bangladesh. J Clin Case Rep 4: 460. doi:10.4172/2165-7920.1000460

Copyright: $\odot 2014$ Shahrin L, et al. This is an open-access article distributed under the terms of the Creative Commons Attribution License, which permits unrestricted use, distribution, and reproduction in any medium, provided the original author and source are credited. 
income family (family income $20,000-25,000 /$ month equivalent to USD $257-321 /$ month) living in a densely populated area in Dhaka city was brought to Dhaka Hospital of the International Centre for Diarrhoeal Disease Research, Bangladesh, Dhaka, Bangladesh. The young infant was admitted at the Longer Stay Unit with the history of watery stool for 2 days, and irritability for 12 hours prior to admission. His stool frequency was 12-15 times/day and no visible blood or mucus was found in the stool and no history of vomiting, fever, or rash was noted. He was fed $300 \mathrm{ml}$ of glucose based ORS which was appropriately diluted over 24 hours prior to coming at the hospital. Plain water was also offered along with breast milk when he became thirsty at home. The child had passed urine four hours prior to admission. Soon after admission, he developed generalized tonic clonic convulsion that persisted for 2 to 3 minutes and he was transferred to the ICU for appropriate investigation and further management.

On further enquiry about his past illness in the ICU, it was revealed that the infant was having watery diarrhoea since day 3 of his birth. During the early days, the parents thought the watery consistency of his stool was cause by breast milk. But they became worried when he was gradually losing weight and became lethargic. At which point they took him to a local private hospital on day of life 8 for diarrhoea, where he was diagnosed as a case of suspected neonatal sepsis (absence of growth in blood culture). Initial blood biochemistry revealed hypernatremia (Serum Na+ $178.5 \mathrm{mmol} / \mathrm{L}$ ). He was treated with IV Ceftazidime for 7 days for sepsis and discharged after spontaneous normalization of serum sodium. However, there was no significant improvement of diarrhoea as per parent's statement. Parents again hospitalized the baby on day of life 20 for increased stool frequency and low urine output. A repeat serum electrolyte and creatinine revealed hypernatremia (Serum $\mathrm{Na}+$ of $178 \mathrm{mmol} / \mathrm{L}$ ) again and acute kidney injury (Serum creatinine $148 \mu \mathrm{mol} / \mathrm{L}$ ), based on the presence of thermo-instability, tachycardia and altered mental status with abnormal WBC count, he was then also diagnosed to have sepsis [12] and managed with IV Imipenem for 10 days and discharged after 25 days of the second admission. Although having clinical features of septicaemia, nothing grew on blood or stool culture, in the both admissions. However, there was no improvement of stool consistency. Later, he had been admitted to a different nonspecialized clinic in the Dhaka city and received several medications without any improvement of diarrhoea.

The young infant was the fifth child of his consanguineous parents. He was not immunized and exclusively breast-fed. His mother was a 38 years old obese lady with a complicated obstetric history. Her first child (female) and $3^{\text {rd }}$ child (male) died during neonatal period due to respiratory difficulty. The two other children were breast fed during the first year and have been healthy. During her last pregnancy she was diagnosed with Gestational Diabetes Mellitus and hypertension and treated with IV Insulin and Tablet Methyldopa. She developed polyhydramnios in her last trimester and underwent cesarean section delivery due to decreased fetal movement. The infant was born full term and weighed $3.5 \mathrm{~kg}$ at birth. He was exclusively breastfed since birth. His developmental milestones were age appropriate.

On examination in the ICU, the infant was restless and inconsolable by his mother. His pulse rate was 138/minute with normal pulse volume, blood pressure was $90 / 50 \mathrm{~mm}$ of $\mathrm{Hg}$, per rectal temperature was $36.6^{\circ}$ C, respiratory rate was $40 /$ minute and arterial oxygen saturation was $99 \%$ on room air. His body weight and length was $2.7 \mathrm{~kg}$ and $51 \mathrm{~cm}$ respectively; which was <-3 Z-score when compared to WHO MGRS Growth Standard for all the anthropometric indices (i.e weight-forage, weight-for-length, and length-for-age). He did not have cyanosis,

jaundice, oedema, dehydration, and he had normal fontanels. There was no neck stiffness and neurological examination revealed to be normal. His blood glucose was $7.0 \mathrm{mmol} / \mathrm{L}$, measured at the bedside during the first episode of convulsion and fundoscopy examination was normal.

The initial problems listed were: a) persistent diarrhoea, b) severe acute malnutrition, c) hypernatremia (on the basis of history and cardinal clinical signs). The laboratory work up on day of admission included: complete blood count, blood culture serum electrolytes including calcium and magnesium, serum creatinine, stool for routine and microscopic examination, rectal swab culture for isolation and identification of salmonella, shigella or vibrio cholerae; urine for microscopic examination and culture. In addition, lumber puncture for cerebrospinal fluid study was done for cytology, biochemistry and culture, which came normal. Results are shown in Table 1.

Convulsion was controlled by IV Phenobarbitone. Watery diarrhoea was managed with oral zinc sulphate and ORS solution for the ongoing loss. Initial management was advised as per management guidelines for children suffering from severe acute malnutrition [13]. Urine and stool microscopy was within normal limits. Stool culture yielded no growth of salmonella, shigella or vibrios. Management of hypernatremic dehydration was started with ORS by calculating the water deficit using the formula that used by Adrogue et al. [9]. The measured ORS was administered using a syringe pump through nasogastric tube. Ongoing loss of stool was matched by ORS in addition. His daily urine output ranges from 75-130 ml. Hypernatremia was corrected over a period of 4.5 days and average rate of fall of serum sodium was $0.2 \mathrm{mmol} / \mathrm{L} / \mathrm{hour}$. Corrected serum sodium: $147 \mathrm{mmol} / \mathrm{L}$ and serum potassium was 4.25 $\mathrm{mmol} / \mathrm{L}$.

On subsequent days there was no improvement of diarrhoea, rather patient developed signs of some dehydration repeatedly. As his diarrhoea was continued since day 3 of birth, we planned to exclude congenital chloride diarrhoea, cystic fibrosis and primary immunodeficiency. Congenital chloride diarrhoea was excluded by serum and stool electrolyte and osmolarity, cystic fibrosis by sweat chloride test [14]. Primary immunodeficiency disorders were excluded by immunoglobulin levels, absolute lymphocyte count and phagocytic cell count. Complement level could not be done due to restrain of facility. As the infant was less than 18 months of age so according to protocol mother was screened for HIV antibody and found negative.

\begin{tabular}{|l|c|c|c|}
\hline Test & $\begin{array}{c}\text { Result on } \\
\text { admission }\end{array}$ & On 7th day & Normal range \\
\hline Hemoglobin & 10 & 8 & $12.5-17.5 \mathrm{gm} / \mathrm{dl}$ \\
\hline Total Leucocyte count & 7.85 & 7.7 & $4.0-11.0 \times 10^{\wedge} 9$ \\
\hline Neutrophil & 44.6 & 36.5 & $40-75 \%$ \\
\hline Lymphocyte & 49.7 & 55.8 & $20-45 \%$ \\
\hline Serum sodium & 168 & 147.7 & $135-146 \mathrm{mmol} / \mathrm{L}$ \\
\hline Serum potassium & 3.21 & 4.25 & $3.5-4.5 \mathrm{mmol} / \mathrm{L}$ \\
\hline Serum creatinine & 58.3 & 46.6 & $18-35 \mu \mathrm{mol} / \mathrm{L}$ \\
\hline Stool pH & 5.95 & & $\mathrm{mosmol} / \mathrm{kg}$ \\
\hline Stool osmolality & 747 & & $\mathrm{mmol} / \mathrm{L}$ \\
\hline Stool sodium & 31 & & $\mathrm{mmol} / \mathrm{L}$ \\
\hline Stool potassium & 24.72 & & $\mathrm{mmol} / \mathrm{L}$ \\
\hline Stool chloride & 37 & & $7.36-7.44$ \\
\hline Stool TCO & 12.92 & & $36-44 \mathrm{mmHg}$ \\
\hline Arterial pH & 7.33 & & $21-27 \mathrm{meq} / \mathrm{L}$ \\
\hline $\mathrm{PCO}_{2}$ & 34.7 & & \\
\hline $\mathrm{HCO}_{3}$ & 18.2 & & \\
\hline & Table 1: Initial and subsequent investigations. & \\
\hline
\end{tabular}




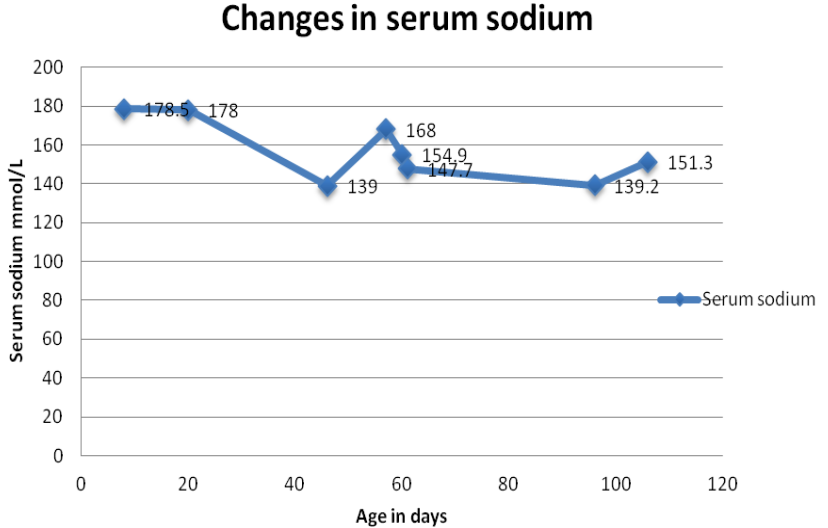

Figure 1: Changes of serum sodium level during hospitalization.

Stool electrolyte, osmolarity, and osmotic gap (176 mOsm/L) suggested osmotic diarrhoea. As per dietary algorithm of icddr,b [15]. Lactose free soy based diet was started and continue for 3 days but no improvement of diarrhoea was observed. Stool culture was repeated on 9 days of hospitalization. It was positive for rota virus but no other bacterial isolation was found. The diet was changed to chicken based $\operatorname{diet}\left(3 / 4^{\text {th }}\right.$ strength comminuted chicken soup) and continued. Within 2 days on chicken based diet his stool became soft and frequency was reduced and showed gradual clinical improvement with weight gain $(2.9 \mathrm{~kg})$. With the advice of the same chicken based diet, the patient was discharged and asked to come for a follow-up visit after 7 days. Due to hypernatremia related convulsion, an Electro Encephalogram (EEG) and Magnetic Resonance Imaging (MRI) scan of brain was performed upon discharge. The EEG showed normal sleep EEG findings and MRI showed haemorrhage within the choroid plexus of the occipital horn of the right lateral ventricle (Figure 1).

Seven days later at home, he again developed watery stool along with low grade fever and was hospitalized again. This time his body weight reduced to $2.7 \mathrm{~kg}$ (Figure 2) and temperature was $38^{\circ} \mathrm{C}$. All the routine investigations were repeated. Stool routine examination was normal. Based on development of new onset of fever and respiratory difficulty after discharge from hospital, patient was categorized as nosocomial infection based on hospital guideline [7]. IV Ceftazidime and IV Amikacin was started for broad empiric coverage for most nosocomial infection [15]. In the repeated laboratory test, blood haemoglobin dropped from $10 \mathrm{gm} / \mathrm{dl}$ to $8 \mathrm{gm} / \mathrm{dl}$ but total WBC count was within normal range. As diarrhoea was not improving, predigested hydrolyzed medium chain triglyceride formula [Pregestimil; Mead Johnson, USA] was started [16] and continued for 3 days. During this period vomiting increased and patient became dehydrated even after adequate oral rehydration. The dehydration was corrected by IV saline according to the protocol for severe dehydration in severely malnourished child [13]. Blood, urine and stool culture and sensitivity tests were repeated to identify the potential causes. Stool culture revealed growth of Campylobacter and Shigella species (Table 2), so oral Azythromycin was added with the ongoing antibiotics. On day 8 of hospital admission, serum electrolyte revealed recurrence of hypernatremia (serum sodium $152 \mathrm{mmol} / \mathrm{L}$ ) that was corrected slowly as previous by G-ORS (corrected serum sodium $143 \mathrm{mmol} / \mathrm{L}$ achieved after 48 hours). Due to continued vomiting despite of our ongoing efforts we decided to keep the patient nothing per oral with intravenous fluid and glucose for correction of dehydration and ongoing stool losses. We could not perform endoscopic small bowel biopsy due to lack of facility. In Bangladesh, there are no facilities for total parenteral nutrition; intravenous glucose infusion was used to provide the daily energy requirement. On 25 day of hospitalization patient developed fast breathing, lower chest wall in-drawing, crackles in both lungs and radiological patchy opacities in both sides. Based on this findings patient was categorized as severe pneumonia and IV Meropenem was started added to cover resistant gram negatives organisms. Nevertheless, the patient developed frequent episodes of hypoglycemia followed by severe sepsis (Pulse-110 b/min, BP 60/30 mm-Hg, mean arterial pressure $\leq 50 \mathrm{~mm}-\mathrm{Hg}$, random blood glucose $2.6 \mathrm{mmol} / \mathrm{L}$ ), that was manage by fluid resuscitation. Simultaneously due to deteriorating clinical condition IV Vancomycin (Table 3) was added to cover Methicillin

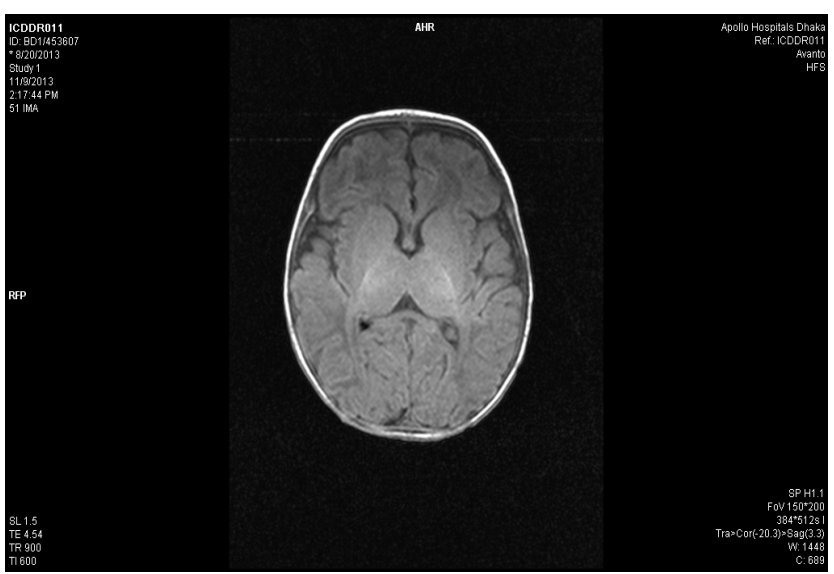

Figure 2: Image of MRI of brain during discharge

Figure shows: Bleeding within the choroid plexus of occipital horn of right lateral ventricle; No detectable evidence of any congenital abnormality or any focal lesion within the brain parenchyma.

\begin{tabular}{|c|c|c|c|}
\hline $\begin{array}{c}\text { Hospital } \\
\text { day }\end{array}$ & $\begin{array}{c}\text { Isolation of organism } \\
\text { in Blood }\end{array}$ & $\begin{array}{c}\text { Isolation of organism } \\
\text { in Urine }\end{array}$ & $\begin{array}{c}\text { Isolation of organism } \\
\text { in stool }\end{array}$ \\
\hline Day 1 & No growth & No growth & No growth \\
\hline Day 5 & Not done & Not done & No growth \\
\hline Day 9 & Not done & Not done & Rota virus \\
\hline Day12 & $\begin{array}{c}\text { Staphylococcus } \\
\text { hemolyticus }\end{array}$ & Klebsiella species & No growth \\
\hline Day 42 & No organism & Escherichia coli & $\begin{array}{c}\text { Campylobacter } \\
\text { species }\end{array}$ \\
\hline & & & Shigella species \\
\hline
\end{tabular}

Table 2: Isolation of organism in total hospital staying period.

\begin{tabular}{|c|c|c|c|}
\hline Name of antibiotics & Cause of illness & Starting day & Duration \\
\hline Oral Azithromycin & Suspected dehydrating Cholera & $\begin{array}{c}\text { On } \\
\text { admission }\end{array}$ & $\begin{array}{l}\text { Single } \\
\text { dose }\end{array}$ \\
\hline IV Ampicillin & $\begin{array}{l}\text { Acute malnutrition with } \\
\text { suspected sepsis }\end{array}$ & $\begin{array}{c}\text { On } \\
\text { admission }\end{array}$ & 7 days \\
\hline \multicolumn{4}{|l|}{ IV Gentamycin } \\
\hline IV Ceftazidim & Deterioration of sepsis & Day 8 & 7 days \\
\hline \multicolumn{4}{|l|}{ IV Amikacin } \\
\hline IV Ceftazidim & Suspecting nosocomial infection & Readmission & 7 days \\
\hline \multicolumn{4}{|l|}{ IV Amikacin } \\
\hline Oral Azithromycin & Campylobacter infection & Day 9 & 5 days \\
\hline IV Meropenem & $\begin{array}{l}\text { Deteriaration of nosocomial } \\
\text { infection }\end{array}$ & Day 15 & 7 days \\
\hline IV Vancomycin & Suspecting MRSA & Day 17 & 5 days \\
\hline
\end{tabular}

Table 3: Receiving of antibiotics during hospitalization. 
Resistant Staphyolococcus aureus (MRSA) following hospital protocol. To manage recurrent hypoglycemia, strength of glucose content in intravenous fluid was increased (5\% to $7.5 \%)$. Fluid resuscitation failed to restore the circulation as the patient developed septic shock that he was started on dopamine. However, the patient developed dopamine resistant septic shock. Despite protocolized management of septic shock according to surviving sepsis guideline patient did not survive. The cause of death was believed to be ionotrop resistant septic shock and antecedent causes were nosocomial infection with intractable diarrhoea and severe acute malnutrition.

\section{Discussion}

To our knowledge, this is the first case study in a young infant that reported the important co-morbidity of intractable diarrhoea: recurrent hypernatremia, severe acute malnutrition, and hospital acquired sepsis. The purpose of reporting this case is to highlight the management difficulties of intractable diarrhoea and the significant co-morbidities in such children in resource poor settings.

Intractable diarrhoea is a common and fatal condition during childhood. Injury to the small intestinal epithelium is the central pathophysiological event that leads to fluid, electrolytes loss and malabsorption of nutrients [17]. It is difficult to identify causes of intractable diarrhoea without invasive techniques [2]. To identify the cause of intractable diarrhoea we followed laboratory investigations by stool microscopy, culture, $\mathrm{pH}$, electrolyte and osmolarity; however, at that time stool for fat and reducing substance measurement at the facility was unavailable. We could not perform colonoscopy biopsy due to debilitated condition of the patient. The expected microscopic features of intractable diarrhoea by colonoscopy described by previous case reports are microvillus atrophy, crypt hyperplasia and microvillus inclusions within the epithelium [18]. Though we could not perform the colonoscopy, based on the definition of intractable diarrhoea given by Avery et al. [2]. Our case fulfilled the criteria of intractable diarrhoea of infancy which is defined as a syndrome, characterised by diarrhoea occurring in newborn younger than 3 months lasting for more than 2 weeks with three or more negative stool cultures for bacteria or parasites. The patient was also identified as a case of osmotic diarrhoea based on high faecal osmotic gap (>100 mosmol/l) [16]. During the evaluation of the potential causes of intractable diarrhoea we had few differentials. Although, there was history of polyhydramnios, for congenital chloride diarrhoea it was expected to have hyponatremia, hypochloremia and metabolic alkalosis since neonatal age that was mismatched wetith our case. Another differential was congenital sodium diarrhoea: the history of polyhydramnios, hyponatremia, metabolic acidosis and high fecal sodium content excluded the probability of this in our case. Based on our hospital protocol, we started dietary modification with lactose free formula, which is soy based diet $[15,19]$. As there was no improvement with soy based diet we could exclude milk protein allergy. After no improvement within 72 hours we switched to chicken based diet and gradually diarrhoea improved. After 22 days of hospitalization finally the patient was discharged with improvement of diarrhoea with normal vital signs and weight gain.

The probable reason of recurrent hypernatremia in our case is hard to explain. It is unlikely to be iatrogenic, because of the given amount of oral saline provided to the baby was measured meticulously. The causes of recurrent hypernatremia might be due to adrenal insufficiency, intrinsic renal cause or diabetes insipidus. However, the differentials were excluded by normal serum cortisol level, normal urine osmolarity and normal blood urea, creatinine and ultrasonography. Previous studies have shown that rota viral diarrhoea is the common cause of hypernatremia in infant and young child [20]. Positive ELISA for rota virus strengthened the relation of hypernatremia in rota viral diarrhoea in our patient in one instance. Nevertheless, the causes of other incidences before hospitalization and during re-admission could not be ensured. One possible cause could be breast milk induced hypernatremia but again due to constrain of laboratory facility we could not evaluate that as well.

In our patient there was gradual loss of body weight which led to severe acute malnutrition ( $\mathrm{WLZ}<-3.5$; WAZ $<-3.09$ ). This finding is consistent with the other reports of IDI. In intractable diarrhoea the mucosal injury persists for prolonged periods which precipitates malnutrition, on the other hand malnutrition impairs the normal proliferative and regenerative responses by crypt epithelium and villous damage and lengthens the intractable diarrhoea [20,21].

Diarrhoea improved with dietary intervention but recurred again along with fever due to prolonged hospital stay. Potential risk factors for developing hospital acquired sepsis in this patient were extreme young age, severe acute malnutrition, intractable diarrhoea and co-morbid conditions like pneumonia.

During the management we have faced some limitations as follows. Firstly, we could not arrange tests such as stool for reducing substances, fat estimation, intestinal biopsy, which could have helped us to reach a more definitive diagnosis. Secondly, we could not arrange total parental nutrition due to lack of facility that may precipitate a nosocomial infection followed by death.

\section{Conclusions}

The strength of the article is the detail description of difficulty in managing a young child with intractable diarrhoea with limited resources due to the many complications that arise from the diarrhoea itself. Whereas, weakness of the article is due to lack of autopsy we could not reach a final diagnosis of the patient, which could be a good learning. These observations would further help health professionals to generate research hypothesis on risk factors and aetiology of intractable diarrhoea in infancy as well as developing a systematic approach to working up intractable diarrhoea in the limited resource setting.

\section{References}

1. Kosek M, Bern C, Guerrant RL (2003) The global burden of diarrhoeal disease as estimated from studies published between 1992 and 2000. Bull World Health Organ 81: 197-204.

2. Avery GB, Villavicencio O, Lilly JR, Randolph JG (1968) Intractable diarrhea in early infancy. Pediatrics 41: 712-722.

3. World Health O (1985) Diarrhoeal Disease Control Programme: persistent diarrhoea in children research priorities. Geneva: World Health Organization.

4. Baqui AH, Sack RB, Black RE, Haider K, Hossain A, et al. (1992) Enteropathogens associated with acute and persistent diarrhea in Bangladeshi children less than 5 years of age. J Infect Dis 166: 792-796.

5. Black RE (1993) Persistent diarrhea in children of developing countries Pediatr Infect Dis J 12: 751-761.

6. Gambarara M, Diamanti A, Ferretti F, Papadatou B, Knafelz D, et al. (2003) Intractable diarrhea of infancy with congenital intestinal mucosa abnormalities: outcome of four cases. Transplantation proceedings.

7. Chisti MJ, Pietroni MA, Smith JH, Bardhan PK, Salam MA (2011) Predictors of death in under-five children with diarrhoea admitted to a critical care ward in an urban hospital in Bangladesh. Acta Paediatr 100: e275-279.

8. Bruck E, Abal G, Aceto T Jr (1968) Pathogenesis and pathophysiology of hypertonic dehydration with diarrhea. A clinical study of 59 infants with observations of respiratory and renal water metabolism. Am J Dis Child 115 122-144. 
Citation: Shahrin L, Chisti MJ, Huq S, Munirul Islam M, Golam Faruque AS, et al. (2014) Intractable Diarrhoea with Recurrent Hypernatremia: Experiences of Management Difficulties from a Diarrhoeal Treatment Centre of Bangladesh. J Clin Case Rep 4: 460. doi:10.4172/21657920.1000460

9. Adrogué HJ, Madias NE (2000) Hypernatremia. N Engl J Med 342: 1493-1499.

10. Chisti MJ, Pietroni MA, Alom MS, Smith JH (2012) Use of Only Oral Rehydration Salt Solution for Successful Management of a Young Infant with Serum Sodium of $201 \mathrm{mmol} / \mathrm{L}$ in an Urban Diarrhoeal Diseases Hospital, Bangladesh. Journal of health, population, and nutrition. 2012; 30: 371.

11. Lima AA, Fang G, Schorling JB, Albuquerque L, McAuliffe JF, et al. (1992) Persistent diarrhea in Northeast Brazil: etiologies and interactions with malnutrition. Acta Paediatrica 81: 39-44.

12. Shahunja K, Shahid SB, Mohammad AS, Ashraf H, Faruque G, et al (2013) Predictors of Death in Under-Five Children with Sepsis Attending an Urban Diarrheal Treatment Centre in Bangladesh. Food \& Nutrition Sciences. 4:

13. Ahmed T, Begum B, Badiuzzaman, Ali M, Fuchs G (2001) Management of severe malnutrition and diarrhea. Indian J Pediatr 68: 45-51.

14. Hihnala S, Höglund P, Lammi L, Kokkonen J, Ormälä T, et al. (2006) Longterm clinical outcome in patients with congenital chloride diarrhea. J Pediatr Gastroenterol Nutr 42: 369-375.

15. Ashraf bH, Ahmed S, Fuchs GJ, Mahalanabis D (2002) Persistent diarrhoea: associated infection and response to a low lactose diet. J Trop Pediatr 48: 142-148.
16. Roy SK, Alam AN, Majid N, Khan AM, Hamadani J, et al. (1989) Persistent diarrhoea: a preliminary report on clinical features and dietary therapy in Bangladeshi children. J Trop Pediatr 35: 55-59.

17. Rossi TM (1983) Intractable diarrhea of infancy. J Pediatr Gastroenterol Nutr 2 Suppl 1: S315-320.

18. Castro-Rodríguez JA, Salazar-Lindo E, León-Barúa R (1997) Differentiation of osmotic and secretory diarrhoea by stool carbohydrate and osmolar gap measurements. Arch Dis Child 77: 201-205.

19. Molla AM, Rahman M, Sarker SA, Sack DA, Molla A (1981) Stool electrolyte content and purging rates in diarrhea caused by rotavirus, enterotoxigenic $\mathrm{E}$. coli, and V. cholerae in children. J Pediatr 98: 835-838.

20. Greene HL, McCabe DR, Merenstein GB (1975) Protracted diarrhea and malnutrition in infancy: Changes in intestinal morphology and disaccharidase activities during treatment with total intravenous nutrition or oral elemental diets. J Pediatr 87: 695-704.

21. Rossi TM, Lebenthal E, Nord KS, Fazili RR (1980) Extent and duration of small intestinal mucosal injury in intractable diarrhea of infancy. Pediatrics 66: 730735 